\title{
Awareness and need of dental implant therapy as pertinent to Indian situation: An overview
}

Sir,

The psychological reactions of patients to loss of their teeth generated little concern in the past. However, in this modern era, artificial replacement of missing teeth with dental implants have been an increasingly common and widely accepted option which is often been referred as an affirmative experience by patients with regards to function, cosmetic, and psychological aspects..$^{[1]}$ Undoubtedly, dental implant replacement therapy renders fabrication of implant supported or retained prosthesis with excellent prognosis even in compromised bony conditions where typical removable or fixed prosthesis fails. On an average, the number of dental implants inserted annually worldwide has been estimated to be approximately 1 million. Much work has been done on the clinical aspects of tooth replacement using various implant systems, but there have been few studies addressing their long-term prognostic assessments and patient's attitudes to this alternative treatment. ${ }^{[2]}$

A study in the United States showed that $77 \%$ of those questioned knew about dental implants; however, their chief source of information was the print as well as electronic media and not their dentists. ${ }^{[3]}$ Watzek and associates in 2003 reported mass media (periodicals and television) as the main sources of mostly negative information about dental implants. This actually generates a potential need for dental professionals to know whether patients feel adequately informed and whether what they know reflects reality. ${ }^{[4]}$ Awareness of what patients know about implants can help to match consumer expectations with what can realistically be achieved to ward off a negative image of implant dentists caused by a communication gap and by consumer discontent. It is therefore essential for the dental education system and the governing bodies to create public awareness of implants, sources of information about implants, and understanding of oral implants as a treatment option. Because most of the studies in this perspective have not been done in India, our recommendations are to promote further detailed surveys in both urban and rural populations to learn more about dental implant awareness among the Indian provinces and to further help create a better awareness of this treatment modality and its benefits.

\section{Sukant Sahoo, Suraj R. Suvarna, Karan Sethi, Prince Kumar}

Department of Prosthodontics, Shree Bankey Bihari Dental College and Research Centre, Ghaziabad, Uttar Pradesh, India

Address for the Correspondence:

Dr. Prince Kumar

Department of Prosthodontics, Shree Bankey Bihari Dental College and Research Centre, Masuri, Ghaziabad, Uttar Pradesh, India. E-mail: princekumar@its.edu.in 


\section{REFERENCES}

1. De Bruyn H, Collaert B, Linden U, Bjorn AL. Patient's option and treatment outcome of fixed rehabilitation on Brånemark implants. A3-years follow-up study in private dental practices. Clin Oral Implants Res 1977;8:265-71.

2. Grogono AL, Lancaster D, Finger IM. Dental implants: A survey of patient's attitudes. J Prosthet Dent 1989;62:573-6.

3. Tepper G, Haas R, Mailath G, Teller C, Zechner W, Watzak G, et al. Representative marketing oriented study on implants in the Austrian population. I. Level of information, sources of information and need for patient information. Clin Oral Implants Res 2003;14:621-33.

4. Tepper G, Haas R, Mailath G, Teller C, Zechner W, Watzak G, et al. Representative marketing-oriented study on implants in the Austrian population. I. Level of information, sources of information and need for patient information. Clin Oral Implants Res 2003;14:621-33.

\begin{tabular}{|l|l|}
\hline Access this article online & Website: \\
Quick Response Code: & www.jmedph.org \\
\cline { 2 - 3 } & DOI: \\
\cline { 1 - 2 } & \\
\cline { 1 - 2 } & \\
\hline
\end{tabular}

